\title{
Intraoperative Injury
}

National Cancer Institute

\section{Source}

National Cancer Institute. Intraoperative Injury. NCI Thesaurus. Code C78367.

Trauma to the body occurring during a surgical intervention. 